\title{
Prevalence of Type 2 Diabetes Mellitus in Chronic Obstructive Pulmonary Disease and Its Impact on the Severity of Chronic Obstructive Pulmonary Disease among Patients Attending Tertiary Care Center in Central Karnataka, Davangere
}

\author{
Eti Ajit, Kushal Bondade, J. Rakesh', Anup Banur, Priyadarshini Raykar \\ Departments of Pulmonary Medicine and ${ }^{1}$ Community Medicine, SS Institute of Medical Sciences, Davanagere, Karnataka, India
}

\section{Abstract}

Introduction: Diabetes mellitus (DM) is an important and common comorbid condition associated with chronic obstructive pulmonary disease (COPD). The exact prevalence of DM in COPD patients among the Indian population is unknown. Coexisting DM is associated with poor outcome in COPD patients and has a significant impact on lung function and severity of the disease. Aim: The aim of this study was to determine the prevalence of type 2 DM in COPD patients attending tertiary care hospital and to assess its impact on the severity of the disease and exacerbation. Patients and Methods: A cross-sectional study was done at a tertiary care center in Davangere from July to December 2016. Convenience sampling was used to study 412 patients attending the hospital for consultation. An interview schedule consisting of sociodemographic details and GOLD criteria 2015 to diagnose COPD and the World Health Organization criteria for DM was used. Results: The prevalence of DM was $23.05 \%$ (95) among 412 COPD patients studied. Thirty-five $(8.49 \%)$ patients were newly diagnosed with DM. The prevalence in mild, moderate, severe, and very severe COPD was $14.73 \%, 18.94 \%, 36.84 \%$, and $29.47 \%$, respectively. DM group patients had a significant decline in lung function compared to non-DM group (mean forced expiratory volume $1 \%-45.92 \pm 4.22 \mathrm{v} / \mathrm{s} 56.64 \pm 3.58$, $P=0.001)$, and the majority of patients with DM (29.47\%) were in exacerbation when compared to nonDM group (16.71\%). Conclusion: The prevalence of DM is high in COPD patients, and significant numbers are newly detected. Hence, it is crucial to screen all COPD patients for DM routinely. Further diabetics tend to have more severe COPD when compared to nondiabetics.

Keywords: Chronic obstructive pulmonary disease, diabetes mellitus, prevalence, screening

\section{INTRODUCTION}

Noncommunicable diseases (NCDs) such as cardiovascular diseases, stroke, and chronic respiratory diseases pose significant burden on global health, chronic obstructive pulmonary disease (COPD) being one the leading causes of mortality among them. ${ }^{[1]}$ The prevalence of COPD continues to increase worldwide and is projected to be the third leading cause of death by 2030. According to the World Health Organization (WHO) estimates, 65 million people have moderate-to-severe COPD worldwide. Mortality due to COPD in 2005 corresponds to $5 \%$ of all deaths globally. ${ }^{[2]}$

Recently, COPD is considered a disease that has multisystem involvement. Comorbid diseases associated with COPD have a significant impact on the clinical profile and functional

\begin{tabular}{|l|l|}
\hline \multicolumn{2}{|c|}{ Access this article online } \\
\hline Quick Response Code: & Website: \\
\hline
\end{tabular}

capabilities of the individual. Common comorbidities associated with COPD are diabetes mellitus (DM), systemic hypertension, ischemic heart disease, and heart failure. Among these, DM is one of the frequent comorbidities encountered in patients with COPD which can significantly alter the course of the disease.

COPD and DM, both being pro-inflammatory conditions, they share relevant features in their etiology and course. COPD

Address for correspondence: Dr. Kushal Bondade, Department of Pulmonary Medicine, SS Institute of Medical Sciences, Davanagere, Karnataka, India. E-mail: kushalbondade531@gmail.com

This is an open access journal, and articles are distributed under the terms of the Creative Commons Attribution-NonCommercial-ShareAlike 4.0 License, which allows others to remix, tweak, and build upon the work non-commercially, as long as appropriate credit is given and the new creations are licensed under the identical terms.

For reprints contact: reprints@medknow.com

How to cite this article: Ajit E, Bondade K, Rakesh J, Banur A, Raykar P. Prevalence of type 2 diabetes mellitus in chronic obstructive pulmonary disease and its impact on the severity of chronic obstructive pulmonary disease among patients attending tertiary care center in central Karnataka, Davangere. Indian J Respir Care 2019;8:42-5. 
patients are more prone to develop type $2 \mathrm{DM}$ due to multiple risk factors such as obesity, sedentary lifestyle, smoking, increased inflammation, oxidative stress, and corticosteroid therapy. The prevalence of DM in COPD patients is $2 \%-37 \%$ depending on the patient population studied and is consistently associated with a 1.4-2.0 fold increased risk of developing DM..$^{[3]}$

Considering the enormously growing incidence of both DM and COPD in India, the convergence of these two chronic NCDs poses a great challenge to the treating physician. Hence, this study has been taken up to know the prevalence of DM in COPD patients attending our tertiary care center and to know its impact on the lung function and severity of the COPD.

\section{Patients and Methods}

This was a cross-sectional study done during the period of July-December 2016. Institutional ethics approval was obtained for the study. About 412 patients attending for consultation at pulmonary medicine outpatient department in a tertiary care center at Davanagere in central Karnataka were interviewed. A written informed consent was taken before interview. The questionnaire was adapted from the GOLD criteria - 2015 to diagnose COPD according to

\begin{tabular}{lc}
\hline Table 1: Patient demographics $(\boldsymbol{n}=\mathbf{4 1 2})$ & \\
\hline Parameters & Observation \\
\hline Sex (male/female) & $328 / 84$ \\
Age (years), mean \pm SD & $58.4 \pm 11.6$ \\
BMI $\left(\mathrm{kg} / \mathrm{m}^{2}\right)$, mean \pm SD & $23.47 \pm 3.7$ \\
History of smoking $(n)$ & 274 (among men) \\
Smokers & 51 (among women) \\
Biomass fuel exposure & $60(14.56)$ \\
Known DM cases, $n(\%)$ & $35(8.49)$ \\
Newly diagnosed DM cases, $n$ (\%) & $95(23.05)$ \\
Prevalence of DM, $n(\%)$ & \\
Severity of COPD among DM patients, $n(\%)$ & $14(14.73)$ \\
$\quad$ Mild & $18(18.94)$ \\
Moderate & $35(36.84)$ \\
Severe & $28(29.47)$ \\
$\quad$ Very severe & $81(19.66)$ \\
Number of patients in acute exacerbations, $n(\%)$ & \\
\hline SD: Standard deviation, BMI: Body mass index, DM: Diabetes mellitus, \\
COPD: Chronic obstructive pulmonary disease
\end{tabular}

which spirometric criterion postbronchodilator value forced expiratory volume $1\left(\mathrm{FEV}_{1}\right)$ /forced vital capacity $(\mathrm{FVC})<0.70$ was taken. Those found to be diagnosed to have COPD were screened for DM according to the WHO/International Diabetes Federation consensus statement.

The data were entered in Microsoft Excel and analyzed using SPSS Inc. Released 2007. SPSS for Windows, Version 16.0. (Chicago, SPSS Inc.). Measures of central tendency such as mean and standard deviation were used to describe the sociodemographic variables. Test of association such as the Mann-Whitney test and $t$-test were performed to look for association between various sociodemographic and COPD factors. A value of $P \leq 0.05$ was taken to be level of statistical significance.

\section{RESULTS}

Four hundred and twelve patients with COPD were included in the study. Among them, 328 (79.6\%) were male and $84(21.6 \%)$ female. The mean age among study participants was $58.4 \pm 11.6$ years. Mean body mass index of the participants was $23.47 \pm 3.7$. In the present study, number of smokers among males were $274(83.5 \%)$, and none of the females were smokers. About 51 (60.7\%) female participants had a history of exposure to biomass fuel [Table 1].

Among 412 study participants, 95 (23.05\%) had DM and among which $35(8.49 \%)$ were newly diagnosed to be diabetic. The mean duration of COPD in diabetics $(7.06 \pm 2.10$ years $)$ was more when compared to nondiabetics (6.42 \pm 1.98 years), and this difference was found to be statistically significant $(P=0.006)$. Furthermore, significant difference in smoking was seen among diabetics (mean pack years $12.93 \pm 3.11$ ) when compared to nondiabetics $(9.57 \pm 4.68$ years $)(P=0.001)$. Our study showed that there was a severe decline in lung function (mean $\mathrm{FEV}_{1}-45.92 \pm 4.22$ ) in people with diabetes as compared to nondiabetics $(56.64 \pm 3.58)$ and it was found to be statistically significant $(P=0.001)$. Acute exacerbations were seen more in diabetics than nondiabetics with a significant difference $(P=0.008)$ [Table 2].

\section{DISCUSSION}

COPD represents a significant and growing health-care concern as a leading cause of morbidity and mortality

Table 2: Comparison between diabetics and nondiabetics

\begin{tabular}{|c|c|c|c|}
\hline & Diabetics $(n=95)$ & Nondiabetics $(n=317)$ & $P$ \\
\hline Sex (male/female), $n$ & $72 / 13$ & $256 / 71$ & 0.310 \\
\hline Age (years), mean $\pm \mathrm{SD}$ & $59.52 \pm 12.22$ & $57.64 \pm 10.84$ & 0.145 \\
\hline $\mathrm{BMI}\left(\mathrm{kg} / \mathrm{m}^{2}\right)$, mean $\pm \mathrm{SD}$ & $23.66 \pm 4.20$ & $22.84 \pm 3.64$ & 0.064 \\
\hline Smoking (pack years), mean $\pm \mathrm{SD}$ & $12.93 \pm 3.11$ & $9.57 \pm 4.68$ & 0.001 \\
\hline Duration of COPD (years), mean \pm SD & $7.06 \pm 2.10$ & $6.42 \pm 1.98$ & 0.006 \\
\hline $\mathrm{FEV}_{1}$ (percentage predicted), mean $\pm \mathrm{SD}$ & $45.92 \pm 4.22$ & $56.64 \pm 3.58$ & 0.001 \\
\hline Number of patients in exacerbation at the time of enrollment, $n(\%)$ & $28(29.47)$ & $53(16.71)$ & 0.008 \\
\hline $\mathrm{HbA} 1 \mathrm{c}$ levels $($ mean $\pm \mathrm{SD})$ & $9.1 \pm 1.8$ & $5.2 \pm 1.3$ & 0.0001 \\
\hline
\end{tabular}

SD: Standard deviation, BMI: Body mass index, COPD: Chronic obstructive pulmonary disease, FEV : Forced expiratory volume in $1 \mathrm{~s}$, HbA1c: Hemoglobin A1c 
worldwide. India contributes enormously to COPD burden which is estimated to be among the highest in the world. Mortality due to COPD in India is four fold greater than the USA and Europe. ${ }^{[4]}$ This number is expected to expand tremendously due to increasing exposure to tobacco smoking and biomass fuel. COPD is considered as a novel risk factor for new-onset type $2 \mathrm{DM}$ due to chronic inflammation, oxidative stress, insulin resistance, weight gain, and dysfunction of fat metabolism.

On the other hand, the prevalence of DM is increasing rapidly worldwide. India is considered as the diabetes capital of the world with 41 million people having DM, and every fifth diabetic in the world is an Indian. ${ }^{[5]}$ Considering the significant change in the lifestyle, food habits, decreased physical activity, and obesity in the Indian population, there has been escalating epidemic of DM in both rural and urban Indian populations. With India currently experiencing a demographic shift with higher percentage of elderly population, the coexistence of these two chronic disorders in an individual is very high which would worsen the morbidity and mortality of the individual.

The present study showed that DM was found in $23.05 \%$ (95/412). Our findings are in line with other studies done previously. A study conducted in Belgaum, India in 2015 by Mahishale et al. observed that the prevalence of DM in COPD patients was $25.63 \% .{ }^{[6]}$ Few other studies done outside India observed that deranged blood glucose was seen in more than $50 \%$ of the patients admitted with acute exacerbation of COPD. ${ }^{[7-9]}$

Our study showed that a significant number of diabetics $35(8.49 \%)$ was newly detected. They were not aware of their diabetic status. It is proved beyond doubt that COPD is a condition which predisposes to develop new-onset type $2 \mathrm{DM}$. Rana et al. observed that COPD patients had a multivariate relative risk of 1.38 (95\% confidence interval [CI]: 1.14-1.67) for new-onset type $2 \mathrm{DM} \cdot{ }^{[10]}$ Feary et al. showed an odds ratio of 2.04 (95\% CI: 1.97-2.12) for the development of new-onset diabetes in COPD patients. ${ }^{[1]}$

Furthermore, the present study showed that COPD patients with DM had statistically significant decline in the $\mathrm{FEV}_{1}$, and duration of COPD was longer and had more exacerbation rates. Our findings are in line with other studies. The third National Health and Nutrition Examination Survey ${ }^{[12]}$ observed declined lung functions in people with diabetes compared to nondiabetics. Another important aspect worth mentioning here is that this impaired pulmonary function is likely to deteriorate rapidly in uncontrolled diabetes. This is in agreement with the Fremantle Diabetes Study ${ }^{[13]}$ which showed that comorbid DM was associated with lower values of $\mathrm{FEV}_{1}$, FVC, peak expiratory flow (PEF), and VC. Recently, in 2013, El-Habashy et al. ${ }^{[14]}$ showed that there was a significant decrease in pulmonary function tests among diabetic patients (FEV1, FEV1/FVC\%, forced expiratory flow $-25 \%-75 \%$, maximal voluntary ventilation, and PEF) compared with healthy controls and further proved that decline was exaggerated in poorly controlled DM.

None or very few Indian studies have compared lung function and exacerbations between diabetics and nondiabetic COPD patients. This is one of the strengths of our research. Our study is limited by small sample size and being a single-center study, and the results cannot be generalized. Some of the patients who were newly diagnosed with DM may be actually having acute transient hyperglycemia due to stress reaction and steroids administration. However, we used $\mathrm{HbA} 1 \mathrm{C}$ to confirm the diagnosis of DM.

\section{Conclusion}

DM is a common comorbidity seen in patients with COPD. A significant proportion of patients with COPD is newly detected DM. These patients are often not aware of their diabetic status. DM significantly affects the clinical course of COPD. Patients with uncontrolled DM have more severe COPD, poor lung function, and more exacerbations.

\section{Financial support and sponsorship}

Nil.

\section{Conflicts of interest}

There are no conflicts of interest.

\section{RefERENCES}

1. COPD Predicted to be Third Leading Cause of Death in 2030. Available from: http://www.who.int/respiratory/copd/World_Health Statistics_2008/en/. [Last accessed on 2015 Aug 22].

2. World Health Organization. Burden of COPD. Available from: http:// www.who.int/respiratory/copd/burden/en/. [Last accessed on 2017 Jan 12].

3. Claire EW and Emma HB. Metabolic syndrome and diabetes mellitus in COPD. In: Klaus FR, Jadwiga AW, Emiel FM. Editor. European Respiratory Mongraph. Vol. 59. 2013. p. 117-34.

4. Salvi S, Agrawal A. India needs a national COPD prevention and control programme. J Assoc Physicians India 2012;60:5-7.

5. Joshi SR, Parikh RM. India - Diabetes capital of the world: Now heading towards hypertension. J Assoc Physicians India 2007;55:323-4.

6. Mahishale V, Mahishale A, Patil B, Sindhuri A, Eti A. Screening for diabetes mellitus in patients with chronic obstructive pulmonary disease in tertiary care hospital in India. Niger Med J 2015;56:122-5.

7. Baker EH, Janaway CH, Philips BJ, Brennan AL, Baines DL, Wood DM, et al. Hyperglycaemia is associated with poor outcomes in patients admitted to hospital with acute exacerbations of chronic obstructive pulmonary disease. Thorax 2006;61:284-9.

8. Chakrabarti B, Angus RM, Agarwal S, Lane S, Calverley PM. Hyperglycaemia as a predictor of outcome during non-invasive ventilation in decompensated COPD. Thorax 2009;64:857-62.

9. Moretti M, Cilione C, Tampieri A, Fracchia C, Marchioni A, Nava S, et al. Incidence and causes of non-invasive mechanical ventilation failure after initial success. Thorax 2000;55:819-25.

10. Rana JS, Mittleman MA, Sheikh J. Chronic obstructive pulmonary disease, asthma, and risk of type 2 diabetes in women. Diabetes Care 2004;27:2478-84.

11. Feary JR, Rodrigues LC, Smith CJ, Hubbard RB, Gibson JE. Prevalence of major comorbidities in subjects with COPD and incidence of myocardial infarction and stroke: A comprehensive analysis using data from primary care. Thorax 2010;65:956-62. 
Ajit, et al.: Type 2 diabetes mellitus and COPD

12. McKeever TM, Weston PJ, Hubbard R, Fogarty A. Lung function and glucose metabolism: An analysis of data from the third national health and nutrition examination survey. Am J Epidemiol 2005;161:546-56.

13. Davis TM, Knuiman M, Kendall P, Vu H, Davis WA. Reduced pulmonary function and its associations in type 2 diabetes: The Fremantle Diabetes Study. Diabetes Res Clin Pract 2000;50:153-9.

14. El-Habashy MM, Agha MA, El-Basuni HA. Impact of diabetes mellitus and its control on pulmonary functions and cardiopulmonary exercise tests. Egypt J Chest Dis Tuberc 2014;63:471-6. 